\title{
Análisis jurisprudencial de la sentencia stc-1976 de 2019 de la corte suprema de justicia de colombia: Un caso de corrección constitucional en la filiación de crianza $^{1}$
}

\author{
Jurisprudential analysis of the judgment stc-1976 of 2019 of the \\ colombian supreme court of justice: a case of constitutional correction \\ in social parenthood
}

\author{
Víctor Julián Moreno MosQuera ${ }^{2}$ \\ Profesor de la Institución Universitaria de Envigado \\ vjmoreno@correo.iue.edu.co
}

John Fernando Restrepo TAMAYO ${ }^{3}$

Profesor de la Universidad de Medellín

jfrestrepo@udem.edu.co

\begin{abstract}
Resumen: El presente comentario de jurisprudencia estudia la Sentencia STC1976 de 2019 de la Corte Suprema de Justicia colombiana, la cual evidencia, como a través de la aplicación axiológica de postulados superiores, la filiación de crianza o social, es congruente con la prevalencia del interés superior de los niños, niñas
\end{abstract}

1 El presente comentario jurisprudencial es derivado de la investigación doctoral, denominada: orden jurídico familiar corregido a partir del constitucionalismo colombiano contemporáneo. Financiado por la Institución Universitaria de Envigado (Colombia).

2 Profesor de la Institución Universitaria de Envigado - Colombia. vjmoreno@correo.iue.edu.co

3 Profesor de la Universidad de Medellín - Colombia. jfrestrepo@udem.edu.co

Comentario recibido el 19.06.2020 y aceptado para publicación el 22.07.2020. 
y adolescentes; en contraste a la lógica conservadora de las reglas ordinarias sobre filiación. Esto es, frente a un mismo problema sobre relaciones filiales donde intervienen menores de edad criados por padres con quienes no comparten vínculo biológico, existen dos soluciones jurídicas antagónicas; donde la respuesta legalista que expone la inflexibilidad del derecho positivo clásico, antagoniza con el principio pro infants, en desarrollo del Bloque de constitucionalidad.

Palabras clave: Filiación de crianza, jurisprudencia constitucional, corrección constitucional.

Abstract: The present jurisprudence commentary studies the STC-1976 Judgment of 2019 of the Colombian Supreme Court of Justice, which evidences how through the axiological application of superior postulates, the parentage of upbringing or social, is consistent with the prevalence of the best interest of children and adolescents; in contrast to the conservative logic of ordinary filiation rules. That is, when faced with the same problem regarding filial relationships involving minors raised by parents with whom they do not share a biological bond, there are two antagonistic legal solutions. On the one hand, the legalistic response that exposes the inflexibility of classical positive law. And on the other, the family constitutional correction where the specific cases are harmonized with the pro infants principle, in development of the Constitutionality Block.

Keywords: Parenting filiation, constitutional jurisprudence, constitutional correction.

\section{Introducción}

La Sentencia que es objeto de comentario jurisprudencial, entraña el siguiente cuestionamiento: ¿es constitucional que una adolescente de 15 años, se niegue a atender el llamado judicial, soportado en la ley vigente, para practicarse una prueba de $\mathrm{ADN}$, cuando el presunto padre biológico que reclama la real filiación no ha aparecido en ese tiempo? Si la respuesta es afirmativa, ¿cómo entender los artículos 386 del Código General del Proceso, el artículo 1 de la Ley 721 de 2001 y, el artículo 1 de la Ley 1060 de 2006 en concordancia con el artículo 406 del Código Civil? Los dos primeros ordenan el imperativo de practicar la prueba de manera diligente y expedita, y los dos últimos, se orientan en favor de la real filiación incluso frente a la prescripción o decisiones judiciales en sentido contrario. Son 
estas cuestiones las que se encarga de resolver la Corte Suprema de Justicia en la Sentencia STC-1976 de 2019, tomando como referencia los precedentes judiciales establecidos por la Corte Constitucional ${ }^{4}$ en materia de filiación de crianza.

Este análisis pretende demostrar que resulta posible comprender la institución jurídica de la filiación en una dirección menos formalista y más ajustada a los lineamientos que sobre la materia ha trazado la Corte Constitucional. Tales pronunciamientos obedecen a una lógica de corrección constitucional en la que un mismo supuesto fáctico puede tener en el orden jurídico respuestas antagónicas en sentido normativo, pero donde la preferencia de una sobre otra se corresponde con la aplicación de un sistema jurídico que se orienta en favor de sujetos de especial protección: niños, niñas y adolescentes; sin que ello signifique una anulación de la seguridad jurídica sino una evolución hermenéutica de los criterios formalistas del Código Civil.

El propósito de este escrito es mostrar de qué manera la institución jurídica de la filiación trasciende los presupuestos legales enmarcados en la condición matrimonial, marital, extramatrimonial o adoptiva, que resultan insuficientes para responder a las reclamaciones ciudadanas de justicia material articuladas al principio de dignidad 5 que profesa un Estado social y democrático de derecho ${ }^{6}$ como el colombiano.

La materialización de las garantías de los hijos de crianza, si bien es cierto han partido de la necesidad de generar beneficios pecuniarios y prestacionales derivados de la muerte del padre, no es menos cierto que esta lógica de articulación doméstica enaltece los vínculos afectivos derivados del cuidado, apoyo y manutención permanentes en el tiempo, todos ellos, hechos loables que encuentran protección constitucional, máxime si se procura en favor de niños, niñas y adolescentes. El constitucionalismo contemporáneo alrededor del derecho familiar propugna por la valentía y la creatividad de sus jueces, quienes deben reconocer en sus fallos las complejas relaciones familiares, y no caer en la visión unívoca de una filiación cerrada por los tres esquemas legalistas de articulación paterno-filial derivados de la presunción ofrecida por el matrimonio y la unión marital, las relaciones sexuales por fuera de éstos o la adopción.

4 Corte Constitucional de Colombia. Sentencia T-281 de 2018. Considerando No. 32.

5 Corte Constitucional de Colombia. Sentencia T-881 de 2002. Considerando No. 6.2.3.

6 Corte Constitucional de Colombia. Sentencia T-406 de 1992. Considerando No.12. 
El instrumento utilizado para realizar este comentario jurisprudencial descansa en: (1) la aplicación del análisis estático ${ }^{7}$ de la Sentencia STC-1976 de 2019; el cual es presentado en un primer momento, para después revisar; (2) el impacto de la Sentencia STC-1796 de 2019 en el sistema tradicional de filiación colombiano; (3) evidenciar como el comentario jurisprudencial materializa la corrección constitucional en clave de filiación de crianza cuando los niños, niñas y adolescentes están integrados a ésta y, (4) reconocer la jurisprudencia constitucional como una herramienta idónea de transformación del sistema legal colombiano en materia de filiación de crianza.

\section{Del análisis jurisprudencial estático de la Sentencia STC-1976 de 2019}

Se trata de un fallo que resuelve la impugnación promovida contra la Sentencia de tutela dictada por la Sala Civil-Familia del Tribunal Superior de Cundinamarca, que a su vez confirmó el fallo dictado por el Juzgado Segundo Promiscuo de Familia de Girardot, en tanto no protegió los derechos fundamentales de la adolescente M.J.V.T, quien rogaba no ser obligada a practicarse una prueba de AND en el marco de un proceso de impugnación e investigación de paternidad. La razón fundante de su negativa partía de la falta de interés en conocer su verdadera filiación biológica, pues durante 15 años había sido criada y amada por un único hombre a quien reconoce como su padre, al igual que sus amigos y compañeros de colegio; además del grave daño que esta situación le causaría psíquica y emocionalmente como adolescente, sumado a la afectación recibida por su familia en términos de estabilidad y armonía. ${ }^{8}$

Como hechos relevantes del caso, se destaca que la actora fue demandada en proceso de impugnación de su vínculo paterno-filial de orden legal, junto a sus padres J.F.V.R y L.G.T.Y, por el presunto padre biológico Javier Capera Quintana. Por su parte, el Juzgado Primero Promiscuo de Familia de Girardot, admitió la demanda el 7 de junio de 2018, ordenando la práctica de la prueba de ADN para el 6 de julio del mismo año, conforme el numeral 2 del artículo 386 del Código General del Proceso y el artículo 1 de la Ley 721 de 2001.

7 LóPEZ, D. (2006). pp 193-264. La finalidad de esta herramienta de interpretación jurídica apunta a la extracción de la ratio decidendi del fallo, la cual debe estar articulada con el problema jurídico y la resolución final que profiere la Corte Constitucional.

8 Corte Suprema de Justicia de Colombia. Sentencia STC-1976 de 2019. Considerando No. 3. 
La parte demandada no asistió a la cita e interpuso un recurso de reposición y en subsidio apelación contra la providencia admisoria, con el ánimo de controvertir la orden judicial. Dentro de las razones aducidas por los representantes legales y judiciales de la adolescente, se encuentran: (i) la caducidad de la acción $y$, (ii) el interés superior de los derechos a la integridad sicológica, social y personal de la adolescente; solicitando así, que fuera escuchada antes de practicar la prueba. El juzgado accionado no atendió los reclamos e ignoró los argumentos de la adolescente, confirmando su providencia bajo la garantía legal que le asiste al padre biológico en atacar el presunto reconocimiento de paternidad, en otrora realizado. Y dispuso nuevamente llevar a cabo la prueba científica; no sin antes iniciar trámite sancionatorio contra el abogado de los demandados por torpedear la realización de la prueba con sus escritos.

La adolescente en cuestión, interpuso acción de tutela, la cual fue resuelta en su contra por el Tribunal Superior de Cundinamarca al negar el amparo rogado y en sentido antagónico validar las razones aducidas del juzgado accionado, pues al no existir sentencia de fondo no podía predicarse vulneración alguna, máxime si se tiene en cuenta que las actuaciones de dicho despacho, están amparadas por la ley vigente. Vale resaltar que el padre biológico demandante, adujo que su supuesta hija adolescente era víctima de manipulación por parte su familia legal. La Sentencia en cuestión fue impugnada, generando así la competencia de la Corte Suprema de Justicia en segunda instancia.

Aunque en la providencia comentada no se expresa en forma taxativa el problema jurídico, sí es posible extraerlo del numeral 4 de su texto. Para la Corte Suprema, el dicho de la adolescente actora, aboga por el respeto al amor, amparo, sostenimiento y bienestar espiritual proveído por el hombre que la reconoció como su hija hace tantos años. Luego, la problemática a resolver radica en si la aplicación legal del artículo 386 del Código General del Proceso, en armonía con el artículo 1 de la Ley 721 de 2001, enmarcado en el auto admisorio de un proceso de impugnación de la paternidad que ordena practicar prueba de ADN; ¿constituye una amenaza contra los derechos fundamentales aducidos por la adolescente, a efectos de mantener la filiación de crianza con el hombre que reconoce psicológicamente como su padre?

Para resolver esta problemática, el presente comentario jurisprudencial identifica como razones ofrecidas por la Corte Suprema de Justicia, aquellas que evidencian una visión correctiva de orden constitucional en materia de filiación de 
crianza, así: (i) la excepcional procedencia de la acción de tutela contra autos interlocutorios, cuando se trata de providencias arbitrarias; con el ánimo de hacer prevalecer el derecho sustancial sobre el excesivo ritualismo procedimental, y evitar la negación de los derechos fundamentales de las partes en litigio, para con ello impedir que el juez accionado avance en la resolución del caso; (ii) impedir la invasión de su esfera privada e íntima de la adolescente, para mantener intacto su nombre y los lazos parentales cohesionados por la crianza recibida desde su primera infancia. Esto efectiviza la garantía prevalente y superior de sus derechos fundamentales a "pertenecer a una familia y no ser separada de ella, identidad, personalidad jurídica, autodeterminación, libre expresión de su opinión y libre desarrollo de la personalidad..."9.; (iii) la aplicación directa del Bloque de Constitucionalidad, utilizando la Convención sobre los Derechos del Niño, que establece el derecho de los menores a ser cuidados por sus padres, a preservar su identidad y nombre ${ }^{10}$, al igual que la materialización de los mandatos constitucionales sobre el derecho que tiene todo menor a tener una familia y no ser separado de ella ${ }^{11}$, dado que la familia es un espacio privilegiado en el cual niños y adolescentes construyen sus referentes de identidad personal y social, por lo que alterar indebidamente esta construcción configura un desarraigo que lesiona la evolución afectiva y psicológica.

Para la Corte Suprema de Justicia la filiación está ligada, en forma íntima, con la realidad de las relaciones humanas, las cuales con el pasar del tiempo consolidan y estructuran el libre desarrollo de la personalidad, que a su vez se armoniza con los postulados axiológicos de dignidad y autodeterminación. El mundo contemporáneo contiene nuevas configuraciones familiares que trascienden los lazos de sangre, siendo la afectividad el criterio prevalente para reconocer la constitución de una relación de parentesco. La Corte Suprema de Justicia soporta estas aseveraciones en la doctrina psicoanalítica y jurídica norteamericana, alusiva al concepto de paternidad psicológica. Esto significa que la mera progenitura, vacía de contacto y actividad, no es oponible a la experiencia conjunta de la convivencia cotidiana entre un niño y un adulto. Es la cercanía relacional que vivencia el amor y el cariño a nivel sicológico el factor determinante para la creación de vínculos

9 Corte Suprema de Justicia de Colombia. Sentencia STC-1976 de 2019. Considerando No. 6. 10 Organización de las Naciones Unidas. Declaración de los Derechos del Niño. 1959, Artículo $7^{\circ}$.

11 Constitución Política de Colombia. 1991. Artículo 44. 
emocionales que desplazan la condición procreadora formal y que se conocen bajo la figura de "paternidad socioafectiva".

Sostiene la Corte Suprema de Justicia que los lazos familiares se sustentan en el derecho fundamental al amor de niños, niñas y adolescentes y al deber de solidaridad familiar que atienden sus demás integrantes en el marco de la unidad familiar. Así, la prueba de ADN como elemento propio del derecho procesal no es oponible a los contenidos axiológicos de la paz y la armonía familiar de crianza. Y la seguridad jurídica es reinterpretada en clave de respetar el lazo afectivo consolidado en la relación funcional de parentalidad que reconoce la adolescente accionante, oponiéndose al frío llamado que hace la ley para reconocer la realidad biológica.

El juez accionado omitió valorar las garantías espirituales, intelectuales y materiales proveídas por la paternidad de crianza; donde la educación, la manutención y el amor se materializan en una huella indeleble de tipo emocional que merece el respaldo estatal. Los jueces deben estar a la altura de los retos constitucionales de garantizar el bienestar integral de niños, niñas y adolescentes, manteniendo la superioridad de sus intereses contrastados con el contexto real de su ambiente familiar y considerando la garantía de escuchar a los menores en tanto su capacidad jurídica de autodeterminación interna.

La Corte Suprema de Justicia es categórica en reconocer el precedente proferido por la Corte Constitucional sobre la transformación del modelo familiar tradicional y la obligación impuesta a los jueces en los procesos de impugnación e investigación de la paternidad de interpretar el orden jurídico de una forma integral y razonable, más allá de la incuestionable y arbitraria autoridad. En este sentido, propone una solución sistémica del problema, donde se articula el principio de interés superior del menor, con el artículo 116 del Decreto 1260 de 1970 referido a los eventos en que la prueba de $\mathrm{ADN}$ es considerada contraria al derecho a la intimidad.

Luego, la aplicación exegética y legalista de los artículos 1 de la Ley 721 de 2001 y el artículo 386 del Código General del Proceso, referidos a la práctica coercitiva del examen genético, si bien persiguen el derecho a saber el verdadero origen biológico, este conocimiento termina siendo facultativo frente a la voluntad del hijo y su vínculo preexistente. Para la Corte Suprema de Justicia es claro que la seguridad jurídica del estado civil consolidado en el vínculo socio-afectivo vivenciado entre la adolescente tutelante y su padre legal prevalece sobre la verdad biológica, 
lo que significa la tutela del derecho al interés superior alegado. Por tanto, ordenó dejar sin efecto las providencias de la autoridad judicial accionada tendientes a investigar la paternidad de la adolescente accionada, quedando incuestionable su vínculo legal; y proceder a archivar la demanda de impugnación.

\section{Del impacto de la Sentencia STC-1796 de 2019 en el sistema tradicional de filiación colombiano.}

La importancia del presente comentario jurisprudencial radica en que la Corte Suprema de Justicia, en sala de tutela, superpone el sistema de principios y valores constitucionales en favor de los derechos de una adolescente, por encima del aparato institucional de la filiación contenida en el Código Civil. La tradición interpretativa civilista en esta materia, está profundamente relacionada con las raíces patriarcales del exegético Código napoleónico, que a su vez sirvió como fuente material para determinar el Código Civil chileno, del cual bebió el proyecto regeneracionista que articuló la República conservadora de 1886 en Colombia ${ }^{12}$. Esto significó la protección de la progenitura legítima masculina como fuente de poder en las relaciones familiares. Los hijos habidos por fuera del matrimonio carecían de derechos y eran denominados de manera peyorativa ${ }^{13}$. La protección jurídica del paradigma patriarcal erigía al matrimonio como referente de autoridad doméstica frente a las mujeres y los hijos ${ }^{14}$.

El artículo 406 del Código Civil consagró la acción de reclamación del estado civil en favor del verdadero padre o madre contra quienes se presenten como padres de su verdadero hijo. “... esta acción de reclamación implica el ataque a la presunción de paternidad, por lo cual toma aspectos de la impugnación, que son de fondo: así, quien pasa por padre no lo es." ${ }^{15}$ Esto significa, que a pesar de la seguridad jurídica que avalaba las relaciones paterno filiales derivadas del matrimonio, existía un excepcionalísimo evento en que podría discutirse la real filiación, por fuera del sistema de impugnación de la paternidad asignado al marido, pues en este evento, ni el hijo, ni la mujer, serían escuchados por el Estado.

El comentario jurisprudencial aquí avocado es congruente con las grandes transformaciones decantadas, en principio, durante el siglo XX, tales como: (i) la

12 Mirow, M. (2000), pp. 81-116.

13 Mendoza, J. (2018). p. 26.

14 Jaramillo, I. (2013). p. 33-34.

15 Parra, J. (2018). p. 434. 
positivización de los derechos de los hijos extramatrimoniales a partir de la Ley 45 de 1936, y su búsqueda por un trato paritario frente a los hijos legítimos, donde destaca la posesión notoria del estado civil de hijo como una figura que responde al trato público y social asumido por un pretenso padre respecto de otro sujeto tratado como hijo, sin que medie vínculo biológico, pero creando lazos afectivos que garantizan subsistencia, educación y manutención ${ }^{16}$; (ii) la ampliación de las causales de investigación de la paternidad e integración con otros medios probatorios como la práctica de pruebas científicas para apoyar los tradicionales documentos y testimonios con la Ley 75 de 1968; (iii) el trato igualitario de derechos hereditarios entre las distintas clases de hijos, sin considerar su fuente filial según la Ley 29 de 1982; (iv) la práctica obligatoria de la prueba de ADN en los procesos de filiación, bien sea para impugnar o investigar la paternidad, bajo un trámite expedito y preferente para excluir o incluir la relación biológica de parentesco, con una probabilidad del 99.99\%, reivindicando así, la búsqueda del real origen parental, de conformidad con la Ley 721 de 2001, la cual subrogada por la Ley 1564 del 2012, para articular dicho proceso preferente a las reglas de la oralidad, pero sin perder de vista la importancia de la prueba científica y, (v) otro cambio relacionado con el comentario jurisprudencial, descansa en la impugnación de la paternidad legalmente establecida por parte del pretenso padre biológico, de acuerdo con la Ley 1060 de 2006, tal y como ocurrió por parte del señor Javier Capera Quintana quien reclamaba su derecho a ser declarado padre de la adolescente M.J.V.T.

El impacto de esta sentencia objeto de comentario jurisprudencial sobre la tradicional forma de interpretar las relaciones filiales radica en que, según lo antes expuesto, no existen reglas jurídicas predeterminadas por el legislativo que en clave exegética respondan a los reclamos de amparo formulados por la adolescente accionante, en términos de privilegiar su voluntad. En sentido contrario, lo que se encuentra en el orden jurídico legalista colombiano, son normas que apoyan la tesis del padre biológico y con ello, la orden del juzgado de familia accionado, en el sentido de realizar la prueba de ADN.

16 GALLO, A. (2015). p. 51. 


\section{Del reconocimiento de la corrección constitucional en el comentario jurisprudencial}

El soporte jurídico de la Corte Suprema de Justica en la sentencia comentada descansa en el desarrollo jurisprudencial de los principios consagrados en la Constitución de 1991, tales como: (i) amparo de la familia como institución básica de la sociedad $^{17}$; (ii) igualdad ante la ley ${ }^{18}$; (iii) derecho fundamental al reconocimiento de la personalidad jurídica ${ }^{19}$; (iv) libre desarrollo de la personalidad ${ }^{20}$; (v) igualdad de derechos y deberes en favor de $\operatorname{los}_{\text {hijos }}{ }^{21} \mathrm{y}$, (vi) derechos fundamentales superiores en favor de los niños ${ }^{22}$; para garantizar un trato paritario entre las diferentes clases de hijos, sin importar la fuente que origine el vínculo.

Para ello, la Corte Suprema de Justicia se apoyó en los precedentes formulados por la Corte Constitucional, a partir de los cuales se entiende la filiación como un atributo de la personalidad jurídica, relacionado con el estado civil y la dignidad ${ }^{23}$. En tal virtud, el Alto Tribunal, ha amparado por vía de tutela las reclamaciones de filiación de crianza, en múltiples ocasiones. Pero cuando ha sido requerido para regularizar y establecer una condición de igualdad entre los hijos de crianza y las otras modalidades de descendencia, por vía de control constitucional, ha respondido negativamente, aduciendo la imposibilidad de intervenir en la competencia del legislador por cuanto opera una omisión legislativa absoluta ${ }^{24}$. Esta situación destaca la importancia del presente comentario jurisprudencial, pues ante la inexistencia de acción legislativa encaminada a salvaguardar las relaciones familiares sustentadas en el amor, el afecto, y la solidaridad, serán las decisiones en sala de tutela las que corrijan los defectos del sistema legal. Corrección constitucional del derecho significa concebir y aplicar la Constitución como norma primera del orden jurídico ${ }^{25}$. A través de sus principios, valores y derechos básicos que la integran ${ }^{26}$, se traza un horizonte hermenéutico expansivo y vinculante

17 Constitución Política de Colombia. 1991. Artículo 5.

18 Constitución Política de Colombia. Artículo 13.

19 Constitución Política de Colombia. Artículo 14.

20 Constitución Política de Colombia. Artículo 16.

21 Constitución Política de Colombia. Artículo 42.

22 Constitución Política de Colombia. Artículo 44.

23 Corte Constitucional de Colombia. Sentencia C-041 de 2004. Considerando No. 11.2.

24 Corte Constitucional de Colombia. Sentencia C-085 de 2019. Considerando No. 20.

25 García; E. (2001).

26 Araújo, J. (2015), p 153. 
sobre la totalidad del orden jurídico y las demás normas del sistema ${ }^{27}$. El corpus normativo constitucional traza una ruta de comprensión del derecho que habilita al juez constitucional ${ }^{28}$ para crearlo y exigir que toda norma asegure su espectro de validez en tanto se ajuste y se corresponda con los mandatos constitucionales de proporcionalidad y de favorabilidad ${ }^{29}$. Esta visión correctiva constitucional se reconoce en el comentario jurisprudencial avocado en este escrito, toda vez que la hermenéutica aplicada por la Corte Suprema de Justicia supera el modelo formalista, propio de la exégesis francesa, en el que se ubican las decisiones del Juez de familia accionado y del Tribunal Superior de Cundinamarca, en primera instancia de tutela, quienes se inclinan en favor de la previsibilidad de las decisiones judiciales y la defensa de la seguridad jurídica; minimizando así, la actividad judicial a una aplicación literal y objetiva del mandato legal. Este modelo legalista se concibió ajeno a toda pregunta por lo justo para preferir lo legal como criterio exclusivo de la comprensión del derecho ${ }^{30}$.

Sin embargo, la Corte Suprema de Justicia descansa sus argumentos en el ideario comprensivo de la corrección constitucional, utilizando las disposiciones constitucionales como reglas jurídicas autónomas y vinculantes de rango supralegal, sobre las cuales resulta posible, necesario y válido fundar pretensiones y decisiones de pleno derecho. En el caso concreto sometido a comentario es posible advertir la interpretación sistemática ${ }^{31}$, la razonabilidad ${ }^{32}$ la proporcionalidad ${ }^{33} \mathrm{y}$ la discrecionalidad utilizadas por la Corte Suprema de Justicia, cuando toma en consideración durante 15 años un vínculo biológico que no ha sido reclamado y durante ese mismo tiempo, ha crecido un lazo socioafectivo recíproco entre una adolescente y el sujeto que la reconoció como padre; generando una relación edificante y pública de amor, cariño y respeto familiar.

La Corte Suprema de Justicia deja de lado el frío silogismo ${ }^{34}$ y la estricta conexión entre juicio hipotético y sentencia, para dar paso a una articulación multinivel dentro del sistema normativo, al tomar una norma que, por regla general,

27 Guastini, R. (1999).

28 Hesse, K. (2011).

29 Ferrajoli, L. (2014), pp 56-95.

30 CAPella, J. (2008), pp 175-181.

31 Corte Constitucional de Colombia. Sentencia C-054 de 2016. Considerando No. 6.2.1

32 Corte Constitucional de Colombia. Sentencia C-022 de 1996. Considerando No. 21

33 Corte Constitucional de Colombia. Sentencia C-10o de 2004. Considerando No. 16.5

34 García, E. (2013), pp 68-83. 
no se acostumbra a utilizar en materia de filiación, pues contraviene lo dispuesto por la Ley 721 de 2001, como lo es el Decreto 1260 de 1970 y su artículo 116 que exceptúa la práctica de la prueba de ADN en tanto inconveniente respecto del derecho a la intimidad; $y$ armonizarla con los principios constitucionales alusivos a los derechos fundamentales de los niños, niñas y adolescentes y anclar esta tesis a la Convención sobre los Derechos de niño, vía Bloque de constitucionalidad. En este comentario jurisprudencial se evidencia como el derecho se transforma en un ejercicio de argumentación ${ }^{35}$ en el cual la protección irrestricta de los derechos fundamentales ${ }^{36}$ pasa a preferirse sobre la mera aplicación de la ley. La búsqueda de la justicia material recoge todo el sentido de la administración de justicia en el interior de un Estado social de derecho ${ }^{37}$, porque hace posible que se incline la balanza en favor de la población vulnerable, en aras de asegurar equidad y un trato digno que genere beneficios para agentes históricamente invisibilizados o excluidos.

Ahora bien, las tesis presentadas por la Corte Suprema de Justicia responden al cambio de paradigma jurídico ${ }^{38}$ que tuvo lugar en Colombia, luego de la expedición en 1991 de la Carta Magna, con una óptica garantista de las diversas tipologías familiares, desmontando paulatinamente los arquetipos e imaginarios tradicionales apalancados en la legislación civil desde la época de la Regeneración en 1886. Ha sido la jurisprudencia constitucional la encargada de deconstruir el modelo jurídico-político familiar, al integrar postulados axiológicos que irradian el sistema legal, desde el bloque de constitucionalidad como consecuencia directa del proceso de constitucionalización del derecho familiar.

Esto significa la mutación de la visión positivista frente a los derechos familiares, replanteando la esencia de núcleo fundacional, el cual radica en un espectro amplio que rompe con la exclusividad de los vínculos biológicos, la monogamia, la heterosexualidad y la religiosidad. El factor familiar determinante subyace en un ambiente de afecto e interacción emocional que merece reconocimiento estatal. La figura de la familia de crianza y el reconocimiento de su filiación como un vínculo socio-afectivo construido en la cotidianidad de la vida real adquiere un valor superior cuando dichos lazos integran a sujetos de especial protección cons-

35 Atienza, M. (2013), pp 56-69.

36 Chinchilla, T. (2009), p 89.

37 Corte Constitucional de Colombia. Sentencia SU-747 de 1998. Considerando No. 18.

38 LÓpez, D. (2006), pp 27-42. 
titucional como son los niños, niñas y adolescentes. Merecen un trato preferente respecto de la esfera tradicional de regulación en favor de la familia biológica, aplicando los criterios de ponderación y de razonabilidad.

\section{La jurisprudencia constitucional como una herramienta idónea de transformación del sistema legal colombiano en materia de filiación de crianza}

Este reconocimiento de la ampliación de la filiación tradicional a la filiación de crianza, ofrecido en este comentario jurisprudencial, además de estar amparado en el bloque de constitucionalidad, también tiene incidencia en aspectos tales como: (i) la garantía de no incriminación en asuntos penales a los familiares de crianza $^{39}$; (ii) la extensión de los efectos pecuniarios para reclamar perjuicios morales en materia de derecho administrativo ${ }^{40} \mathrm{y}$, (iii) la asunción solidaria de paternidad por crianza para el reconocimiento del derecho pensional en la relación socio-afectiva entre un abuelo y su nieto, a pesar de existir la filiación biológica, esto es, no hay ausencia total de la familia de origen, situación que se acerca al concepto de pluriparentalidad que se ha desarrollado en otras legislaciones, soportado en los principios de solidaridad e igualdad ${ }^{41}$.

La sentencia comentada recogió los criterios desarrollados por la doctrina constitucional en materia de filiación de crianza, y de los cuales destaca para el caso concreto, el relacionado con los vínculos de afecto, respeto, comprensión y protección, pues la defensa férrea y constante de la adolescente accionante para reconocer al hombre que desde niña la protegió abrigándola con su apellido en un registro civil y después refrendó ese acto formal con 15 años de entrega moral y emocional. La angustia y el sufrimiento de la familia socio-afectiva demandada en impugnación, ante la amenaza judicial de ser separados por no compartir un lazo de sangre, no puede ser tolerada por el Estado, cuando el transcurso del tiempo ha bruñido el alma y el corazón de la hija con su padre..$^{42}$ Incluso ante la tradicional interpretación exegética de que las relaciones de crianza están en un vacío legal, tanto sustantivo como procedimental, la Corte Suprema de Justicia ha insistido que la familia se configura en la cotidianidad de las relaciones domés-

39 Corte Suprema de Justicia de Colombia. Sentencia SP-2299 de 2019. Considerando No. 4.1.3.7.

40 Consejo de Estado de Colombia. Sentencia No.29.337 de 2014. Considerando No. 7.

41 Corte Constitucional de Colombia. Sentencia T-074 de 2016. Considerando No. 5.1.2.

42 Corte Constitucional de Colombia. Sentencia T-281 de 2018. Considerando No. 57. 
ticas y es “...lugar metafísico que tiene como ingredientes principales el amor, el afecto, la solidaridad y la protección de sus miembros entre sí, e indudablemente, también a factores sociológicos y culturales." ${ }^{43}$

Si bien es cierto, la interpretación clásica de la filiación en Colombia favoreció a los hijos habidos dentro del matrimonio, invisibilizando las garantías de niños, niñas y adolescentes, para proteger los intereses del padre/marido como pilar del modelo patriarcal, conservador y religioso; no es menos cierto, que el sistema jurídico evolucionó dando cabida a otras formas de filiación, con mayor fuerza, desde la Constitución de 1991. A partir de ahí, como se evidencia en este comentario jurisprudencial, la doctrina constitucional de la Corte Constitucional y de la Corte Suprema de Justicia, se han encargado de filtrar los elementos que amparaban una interpretación tradicional y patriarcal de las relaciones paterno filiales, para atender los principios propios del Estado social de derecho, soportados en la inclusión y la tolerancia en la diferencia de las conformaciones familiares que garantizan los derechos esenciales de sujetos de especial protección.

En tal virtud, uno de los aspectos más destacados del presente comentario, radica en que existe una tesis abstencionista sostenida, incluso por la Corte Constitucional en fallos de constitucionalidad para declarar inexequibles disposiciones legales que afectan la filiación de crianza. Esta otra cara del derecho jurisprudencial, reduce la efectividad de la figura y sigue dejando como única alternativa, mientras no exista desarrollo legislativo sobre la materia, la acción de tutela contra decisiones judiciales que privilegien los vínculos filiales con apoyo legal, bien sea matrimonial, extramatrimonial o adoptivo. Esto es, la protección constitucional procede in situ, y no de manera general, impersonal y abstracta; defendiendo así, la rigurosidad positivista del modelo tradicional y que en situaciones familiares de facto quedan reducidas a la acción de tutela.

Esta postura no es congruente con los otros pronunciamientos judiciales analizados donde se generan derechos y obligaciones articulados al fin superior de salvaguardar el derecho de niños y adolescentes al amor en una familia sin discriminación alguna. Esta negación genera un trato inequitativo para la filiación derivada de una familia de crianza, bajo un argumento injusto, pues implica que el Congreso de la República abra espacio en su agenda legislativa para atender reclamos que se encuentran en la realidad social, máxime si se trata de sujetos

43 Corte Suprema de Justicia de Colombia. Sentencia STC-60o9 de 2018. Considerando No. 22. 
vulnerables, cuyos derechos son prevalentes, de interés superior y no deben ser postergados en su atención.

Lo anterior significa que la justicia material que debe garantizar derechos fundamentales queda aplazada por las lógicas propias del sistema político-jurídico legalista, desconociendo el peso y el valor vinculante de la jurisprudencia constitucional como criterio de corrección edificante del orden jurídico. Estas correcciones constitucionales han creado diferentes efectos jurídicos que son análogamente aplicables a los casos de filiación de crianza, donde existen mecanismos para probar su existencia y su efectividad.

\section{Conclusiones}

Es oportuno finiquitar el presente comentario jurisprudencial bajo la interpretación evolutiva que reconoce la garantía de una Constitución viviente, que a su vez, es resultado de un proceso creciente de visibilidad antiformal de los reclamos de tutela judicial efectiva de niños y adolescentes que encuentran respaldo en las cláusulas constitucionales. A la luz del concepto de corrección constitucional, la filiación de crianza implica el reconocimiento de los hechos sociales consolidados en el tiempo por su cotidianidad, donde se vincula afectiva y emocionalmente a un menor con adultos, que garantizan integralmente una relación de paternidad, generando derechos y obligaciones recíprocas en el marco de la familia de crianza. Esta corrección constitucional afirma un arquetipo familiar no supeditado a las ataduras de la interpretación exegética y literal del derecho privado y civil codificado. La crítica formulada contra el actuar del juzgado accionado, reclama la aplicación del interés superior de la adolescente y sanciona el mayor valor otorgado a la ley procesal ordinaria.

La Corte Suprema de Justicia realiza una extensión interpretativa en clave de corrección constitucional al valorar los argumentos formulados por la adolescente accionante a través de su apoderado judicial en la instancia ordinaria. Según la visión positivista y legalista tradicional los pedidos del abogado en favor de escuchar a la adolescente antes de la práctica de la prueba científica en el proceso de impugnación de paternidad devenían en prematuros y desafiantes de la autoridad judicial conforme el Código General del Proceso y la Ley 721 de 2001, que se caracterizan por la celeridad y la inmediatez.

La Corte Suprema de Justicia rompe con los impedimentos formalistas que ahogan los reclamos de justicia material descritos en el recurso de apelación en 
el trámite ordinario y en las múltiples excepciones de fondo formuladas contra la demanda, que revelaban el miedo a la crasa afectación de la adolescente en su integridad sicológica y social. Por eso el reclamo de reserva y sigilo no era un mero capricho, ni un contestatario levantamiento para desafiar la obstinada autoridad judicial accionada. ¡No! El pedido de la accionante apuntaba a respetar los 15 años de relación estable y armónica con su padre "psicológico", en el marco del amor y la protección. Si bien deben ponderarse los intereses de los padres, biológicos o de crianza, estos estarán contrastados con la prevalencia de la calidad de hijo y la importancia existente en el contexto real y social.

La aplicación de esta corrección constitucional materializa el principio pro infants que ductibiliza el sistema legal al aplicar los postulados axiológicos del interés superior y prevalencia de derechos de niños y adolescentes, para flexibilizar criterios procesales, no limitados al examen exegético de las reglas procesales o sustantivas de orden inferior. Pues, para este caso, acatar la orden de practicarse el examen genético constituye una invasión ilegítima al fuero interno de la adolescente, quien repudia su derecho a conocer su real filiación. No coaccionarla significa respetar la dignidad consolidada en su estado civil de hija de crianza.

\section{Bibliografía citada}

Araújo, J. (2015). “Filosofía o teoría del derecho constitucional”. (Bogotá, Editorial Ibáñez).

Atienza, M. (2013). “Curso de argumentación jurídica”. (Madrid, Editorial Trotta). Capella, J. (2008). "Fruta prohibida”. (Madrid, Editorial Trotta).

Chinchilla, T. (2009). “Qué son y cuáles con los derechos fundamentales?” (Bogotá, Editorial Temis).

Ferrajoli, L. (2014). "La democracia a través de los derechos". (Madrid, Editorial Trotta).

Gallo, A. (2015). "La Filiación: un análisis comparado en la legislación colombiana y el derecho común español." (Bogotá. Editorial Ibáñez).

GARCÍA, E. (2001) “La Constitución como norma y el tribunal constitucional. (Madrid, Editorial Civitas).

García, E. (2013) “Introducción al estudio del derecho". (México, Editorial Porrúa) Guastini, R. (1999). "Distinguiendo: estudios de teoría y metateoria del derecho." (Barcelona. Editorial Gedisa). 
ANÁLISIS JURISPRUDENCIAL DE LA SENTENCIA STC-1976 DE 2019 DE LA CORTE SUPREMA

Hesse, K. (2011). “Estudios sobre la jurisdicción constitucional”, (México, Editorial Porrúa).

Jaramillo, I. (2013). "Derecho de Familia en Colombia: Historias de raza, género y propiedad”. (Bogotá, Editorial Universidad de los Andes).

LóPEZ, D. (2006). "El Derecho de los jueces”. (Bogotá, Editorial Legis).

Mendoza, J. (2018). “Derecho familiar: su emancipación del derecho civil.” (Ciudad de México, Editorial Porrúa).

Mirow, M. (2000) "El poder de la codificación en América latina. Simón Bolívar y el Código de Napoleón." FIU Law. E Collections. pp. 81-116. [Consultado: 8 de septiembre de 2020]. Disponible en: https://ecollections.law.fiu.edu/cgi/viewcontent.cgi article $=1120 \&$ context $=$ faculty_publications

Parra, J. (2018) “Derecho de Familia”. (Bogotá, Editorial Temis).

\section{Jurisprudencia citada}

M.O.G.Z. y otros contra Nación - Departamento Administrativo de Seguridad "DAS". (2014): Consejo de Estado de Colombia 9 de julio 2014. (Sentencia No. 29.337 en Acción de reparación directa). [Consultado: 8 de septiembre de 2020]. Disponible en: https://consejo-estado.vlex.com.co/vid/55662539o.

Brayan Steven Ariza Hernández contra el artículo 1045 (Parcial) del Código Civil. (2019): Corte Constitucional de Colombia 27 de febrero 2019. (Sentencia No. 085 de Acción de constitucionalidad). [Consultado: 8 de septiembre de 2020]. Disponible en: https://www.corteconstitucional.gov.co/relatoria/2019/C-085-19. htm.

Agobardo Córdoba Aragonés, curador legítimo de Pedro Pablo Córdoba Aragonés, contra la sociedad Riopaila Castilla S.A, la Administradora Colombiana de Pensiones -Colpensiones- y la Fundación Gerontológica Luz y Esperanza. (2018): Corte Constitucional de Colombia 23 de julio 2018. (Sentencia No. 0281 de Acción de tutela). [Consultado: 8 de septiembre de 2020]. Disponible en: https:// www.corteconstitucional.gov.co/relatoria/2018/T-281-18.htm .

Miguel Antonio Camargo Peña en representación de su menor hijo Yocimar Stiben Camargo Talero contra del Fondo de Prestaciones Económicas, Cesantías y Pensiones -FONCEP-. (2016): Corte Constitucional de Colombia 9 de julio 2016. (Sentencia No.074 en Acción de tutela). [Consultado: 8 de septiembre de 2020]. Disponible en: https://www.corteconstitucional.gov.co/relatoria/2016/t-o74-16.htm. 
Wilson González Quintero y Rolfe Antonio Marín Ortiz contra el artículo 27 del Código Civil. (2016): Corte Constitucional de Colombia 1o de febrero 2016. (Sentencia No.054 de Acción de constitucionalidad). [Consultado: 8 de septiembre de 2020]. Disponible en: https://www.corteconstitucional.gov.co/ relatoria/2016/C-054-16.htm.

Juan Fernando López Ocampo contra el artículo 24, numeral $3^{\circ}$ del Decreto 1569 de 1998. (2004): Corte Constitucional de Colombia 10 de febrero de 2004. (Sentencia No.10o de Acción de constitucionalidad). [Consultado: 8 de septiembre de 2020]. Disponible en: https://www.corteconstitucional.gov.co/relato$\mathrm{ria} / 2004 / \mathrm{C}-100-04 . \mathrm{htm}$.

Austreberto de Ávila Ríos y otros, y Edwin Campo Vega (personero de El Arenal (Bolivar)) contra Electrocosta S.A. E.S.P.. (2002): Corte Constitucional de Colombia 17 de octubre de 2002. (Sentencia No.881 de Acción de tutela). [Consultado: 8 de septiembre de 2020]. Disponible en: https://www.corteconstitucional.gov.co/relatoria/2002/T-881-02.htm.

Marcela Patricia Jímenez Arango contra los artículos $2^{\circ}$ (parcial) de la Ley 403 de 1997 y el 216 del Decreto 262 de 200o. (2004): Corte Constitucional de Colombia 27 de enero de 2004. (Sentencia No.041 de Acción de constitucionalidad). [Consultado: 8 de septiembre de 2020]. Disponible en: https://www.corteconstitucional.gov.co/relatoria/2004/C-041-04.htm

Jorge Eliecer Raza y Otros contra el Registrador del Estado Civil de Santiago, (Putumayo). (1998): Corte Constitucional de Colombia 2 de diciembre de 1998. (Sentencia No. 747 de Acción de unificación en tutela). [Consultado: 8 de septiembre de 2020]. Disponible en: https://www.corteconstitucional.gov.co/relatoria/1998/SU747-98.htm.

Álvaro Montenegro García contra el artículo 40, literal b, de la Ley 48 de 1993. (1996): Corte Constitucional de Colombia 23 de enero de 1996. (Sentencia No. 022 de Acción de constitucionalidad). [Consultado: 8 de septiembre de 2020]. Disponible en: https://www.corteconstitucional.gov.co/relatoria/1996/C-022-96.htm.

José Manuel Rodríguez contra el Tribunal Administrativo de Bolívar. (1992): Corte Constitucional de Colombia 5 de junio de 1992. (Sentencia No. 406 de Acción de tutela). [Consultado: 8 de septiembre de 2020]. Disponible en: https://www. corteconstitucional.gov.co/relatoria/1992/T-406-92.htm. 
José Manuel Rodríguez contra el Tribunal Administrativo de Bolívar. (1992): Corte Constitucional de Colombia 5 de junio de 1992. (Sentencia No. 406 de Acción de tutela). [Consultado: 8 de septiembre de 2020]. Disponible en: https://www. corteconstitucional.gov.co/relatoria/1992/T-406-92.htm.

M.J.V.T. (menor de edad) contra el Juzgado Segundo Promiscuo de Familia de G. (2019): Corte Suprema de Justicia, Sala de Casación Civil y Agraria de Colombia del 20 de febrero de 2019. (Sentencia No. 1976 sobre Acción de tutela). [Consultado: 8 de septiembre de 2020]. Disponible en: https://corte-suprema-justicia.vlex.com.co/vid/773508129.

Omaira Ávila Ballesteros contra la Sala Penal del Distrito Judicial de Manizales. (2019): Corte Suprema de Justicia, Sala de Casación Penal de Colombia del 14 de mayo de 2019. (Sentencia No. 2299 sobre Recurso extraordinario de casación). [Consultado: 8 de septiembre de 2020]. Disponible en: https://corte-suprema-justicia.vlex.com.co/vid/773508129.

Darine Yesennia Bogotá Pirabán contra la Sala Civil-Familia del Tribunal Superior de del Distrito Judicial Cundinamarca. (2018): Corte Suprema de Justicia, Sala de Casación Civil de Colombia del 9 de mayo de 2018. (Sentencia No. 6009 sobre Acción de tutela). [Consultado: 8 de septiembre de 2020] Disponible en: https://cortesuprema.gov.co/corte/wpcontent/uploads/2018/05/STC60o920181.pdf.

\section{Norma jurídicas citadas}

Congreso de la República de Colombia. Ley 1098 de 2016.

Congreso de la República de Colombia. Ley 1060 de 2006.

Congreso de la República de Colombia. Ley 721 de 2001.

Congreso de la República de Colombia. Ley 29 de 1982.

Congreso de la República de Colombia. Ley 75 de 1968.

Congreso de la República de Colombia. Ley 45 de 1936.

Congreso de la República de Colombia. Ley 57 de 1887.

Organización de las Naciones Unidas. Declaración de los Derechos del Niño. 1959. 
